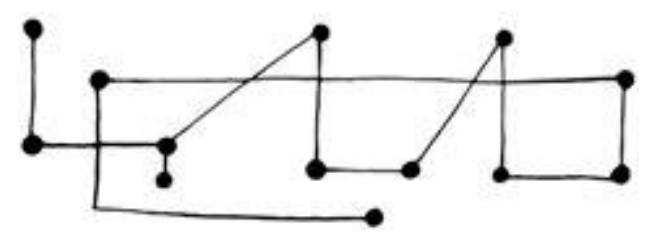

The Frame and The Swerve: Music Video's Relationship to DanceAuthor(s): Brad Osborn Source: Perspectives of New Music, Vol. 57, No. 1-2, Perspectives on and around John Rahn (Summer 2019), pp. 211-221

Published by: Perspectives of New Music

Stable URL: https://www.jstor.org/stable/10.7757/persnewmusi.57.1-2.0211

JSTOR is a not-for-profit service that helps scholars, researchers, and students discover, use, and build upon a wide range of content in a trusted digital archive. We use information technology and tools to increase productivity and facilitate new forms of scholarship. For more information about JSTOR, please contact support@jstor.org.

Your use of the JSTOR archive indicates your acceptance of the Terms \& Conditions of Use, available at https://about.jstor.org/terms 


\section{The Frame and The Swerve: Music VideO'S RELATIONSHIP TO DANCE}

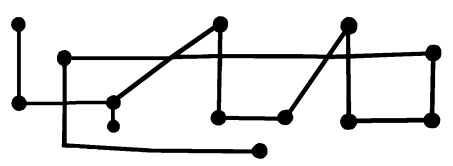

\section{BRAD OSBORN}

$\mathrm{D}$ RAWING FROM THINKERS as diverse as Parmenides, Heraclitus, Nietzsche, and Hegel, John Rahn draws a distinction between two modes of framing the world: Being and Becoming. Being is "the tendency to identify an unchanging essence of things and to sort out the cosmos in terms of such essences,"l while a philosophy of Becoming focuses on "existence rather than essence; change, flux, fire, plasma...."2 For Rahn, this Being/Becoming binary maps neatly onto Lucretius's model of the universe: a frame, in which each unchanging essence falls in neat parallel lines as a stream of atoms, represents the Being strand. What makes the universe interesting for Lucretius-what makes change occur or transforms Being into Becoming - is its propensity for swerve, for one stream of falling atoms to interact spontaneously with another stream. The Being of Lucretius's neat parallel atomic movements represents "the frame of structural (or divine) order" whereas Becoming is engendered by the swerve of "free and artistic will." 3 
Rahn uses this binary opposition to describe some innovative ways that music theorists have used mathematics to talk about music. Theorists of Being focus on "nailing down simple invariant structures such as scales, chords, and pitch class sets, making taxonomies, natural histories," 4 while theorists of Becoming (often composer-theorists) focus on "what might be useful theory for their compositional activity." In true Rahnian fashion, he sets up this binary opposition only to problematize the binary itself: "Turbulence is not free will, laminar flow is not determinism or slavery or totalitarianism (or even bad art)."6

I will use this opposition between Being/frame and Becoming/ swerve (and its eventual destruction) to model what I see as two different ways in which music videos relate to the dance $(r) s$ they depict. The first I'll call choreographed. In choreographed videos, several dancers perform (nearly) identical dances, each body falling in parallel lines within a Lucretian frame. The sounding music, usually played in real time during the video's filming session, could also be described as one of these parallel lines. As Rahn says of Being, "entities do not have to influence each other on the fly and nothing really changes."7 But if we look closely, we can observe slight swerves in which the spontaneous actions cued by that sounding music influence one or more dancers' bodies to fall out of sync, to fall with free will.

Contrast the choreographed dance with the improvised. In this type of music video, several bodies (often playing instruments) interact spontaneously with the sounding music as they trace the audible lines of their recorded artifact. The improvised video is full of flux and swerve. Each dancer is spontaneously influenced not only by the dynamics of the sounding music, but also the other dancers' spontaneous bodily interpretations. Like Becoming, improvised dancing constitutes a complex system of "interacting agents which evolves irreversibly and almost capriciously to a complex organization of its own." 8 Chaos is held together only by the framing music; the musicians must convincingly approximate the bodily movements associated with the heard instrumental music. The music and the dancers are therefore entangled, interweaving a series of horizontal threads.

\section{A Tale of Two Videos}

Like some music theorists, multimedia scholars like typologies. ${ }^{9}$ Music videos have been classified into various types by a number of scholars. Martina Elicker offers a four-part typology: 1) Videos that illustrate the lyrics; 2) Videos that add new meanings that amplify, but do not 
contradict the lyrics; 3) Videos that have no apparent relationship with the lyrics and/or contradict them; and 4) Performance video. ${ }^{10}$

Relative degrees of narrative structure underpin the first three types, proceeding from a video's tightest possible relationship with the lyrics to the loosest. Elicker, Carol Vernallis, and others have developed sophisticated tools and theories to address the difference between the first three types of video. 11 However, the fourth type, the performance video, remains under-theorized. Scholars have often cast aside performance videos as shallow commercial advertisements for their corresponding record. 12 By theorizing a complex relationship between two types of dance contained therein-the choreographed and the improvised-I'll attempt to imbue the performance video with a complexity it is seldom afforded in music video scholarship.

To do this, I'll now turn to Fall Out Boy's emocore hit "Sugar, We're Goin' Down" (2005) and Beyoncé's blistering Katrina-critique "Formation" (2016). On their surface, these are incredibly different videos. The former exemplifies improvisation and the latter choreography. One is by a bunch of white guys, the other features only female performers of color. But both are exceptionally popular; the latter winning the 2016 MTV Music Video Award for best choreography, the former having over 62 million views and the title of "most listened to emo track of all time." 13 Both also are hybrid performance/narrative videos, where either improvised or choreographed performances alternate with scenes in which the video amplifies and adds meaning to the track's lyrics. By analyzing the interactions between frame (choreography) and swerve (improvisation) in each video, I will show how the frame's Being and the swerve's Becoming are in fact intricately entangled.

\section{A. BEYONCÉ, “FORMATION” (2016)}

"Okay ladies/now let's get in formation." This command is directed toward the five to seventeen dancers we see moving in choreographed unison throughout most of the video. Rather than witness the dancers reacting spontaneously to the music, we instead see the scenes and costumes changing, having been pre-arranged and edited to correspond exactly with formal markers. We open with Beyoncé in the center of an "X" formation of five women, all dressed identically and moving in unison in the hallway of an old home filled with wood and antiques. Each dancer is a vertical slice of the frame, in Lucretian terms, a frame of atoms falling "forever in parallel lines." 14 No dancer leaves her designated space, as if held from above by a dangling string. 
At 1:23 the scene changes to an empty swimming pool, the dancers now split into two teams, each team performing a separate choreography. But still no swerve: choreography choreographs itself. As long as we see two or more dancers doing the same thing, we know it's choreographed (in one way or another). ${ }^{15}$ Of course, we can always attend to the micro-timing swerve of human performance discrepancy instead of the choreographed frame, but it's not what's most obvious.

Our first real taste of the swerve comes in the quiet bridge at 2:17. Beyoncé and dancers are back in the antique home, but now they're each dressed in unique antebellum white dresses, fanning themselves at different rates. At a macro-level, sure, the scene is choreographed, but each individual dancer is responding kinesthetically according to her own interpretation of the beat: a sixteenth-based backbeat groove at 61 BPM. Though none is quantized, three dancers in the center of the frame compose a visual accelerando: quarter-note fanning on the left, eighth notes in the center, eighth note triplets on the far right.

But then the bombastic hook comes in, and the ladies snap into formation, now in a new setting with new costumes: throwback blue denim jackets, classic cars. The frame of Being is reimagined as the camera frame itself, as we watch this scene through the simulacrum of a camera operator's viewfinder (the grainy compression, the little "play" triangle in the corner).

The musical material from the fanning scene recapitulates at 3:43. The small amount of swerve we witnessed in the fan speeds is now writ large, with three different populations now shown improvising.

- A young black man dances expressively and defiantly in front of a militaristic vanguard of police.

- Each member of a charismatic congregation of revelers waves their arms and hips to whatever rhythm they feel.

- Beyoncé and her dancers, though still choreographed, now begin a series of "wave" sequences in which each performer is responsible for her own timing according to the movements of those that precede and follow her.

Predictably, when the "formation" hook comes back in, all this swerve comes to a momentary halt. But as swerves seem to coalesce into new Beings, these new Beings, far from stable, immediately enter new phases of Becoming. Along with the musical reprise, we see a visual reprise of both the pool and the parking lot scene-costume 
assemblages. Undoubtedly the most powerful swerve occurs when the police mimic the young man's choreography. At 4:20 (symbolic?) they put down their weapons and assume the "hands up/don't shoot" position, while the camera pans to "stop shooting us" graffiti. The rhythm of frame and swerve in this video is political. The individualistic swerve of African Americans (particularly young African-American men) will be met with violent police resistance, but maybe, if enough of us get in choreographed formation, the state won't (be able to) stop us. Maybe this is wishful thinking.

\section{B. FALL OUT BOY, “SUGAR, WE'RE GOIN’ DOWN” (2005)}

Whereas Beyoncé's video marked formal sections with different settings and costumes, the dancing in Fall Out Boy's video is all in the same room with the same costume. Formal sections, timbral differences, and rhythmic layers are instead marked by different movements. These movements, dances of a sort, swerve along with changes in timbre, volume, and beat speed.

Like so many emo songs, the metric structure of "Sugar" is defined by an immutable subdivision stream $(\AA=320 \mathrm{BPM})$ that alternates between double-time feels $($ beat $=160)$ and half-time feels $($ beat $=80)$. (For convenience, I'll refer to these layers as the sixteenth, eighth, and quarter notes, respectively, though there is of course no reason to invoke notation.)

Throughout the video there is a one-to-one correlation between timbre, volume, and beat speed. The quiet sections, such as verse one $(0: 39)$ and the pre-chorus (1:02), correlate with the drummer playing sixteenth notes on closed hi-hats. In the louder parts of the verse $(0: 50)$, he slows down to eighth notes on the louder open hi-hats, and in the chorus, the loudest section (1:13), he plays these slower eighth notes on a washy crash cymbal.

This system of terracing dynamics, tempo, and timbre between formal sections is part and parcel of modern rock drumming. It also informs the sorts of dancing we see on screen. When the camera zooms in at 0:43 to show the drummer's sixteenth notes on the closed hi-hat, his stick heights are necessarily low and controlled for these faster notes; his head and torso barely move. Similarly, the guitarists' sixteenth note "palm mutes" at l:06, which produce a similarly quiet, controlled sound, keep their feet rooted to the ground, moving only side to side in a gentle sway as they retain the necessary pressure on the strings to dampen the resonance. When the drummer plays the slower, 
louder eighth notes on the open hi-hats at 2:06, he takes advantage of the distended time between attack points to actually make the stick dance side to side. The guitarist and bassist leap (1:14), spin $(2: 24)$, and even toss their guitars into the air $(0: 23)$. They strum along with abandon to the slower quarter-note beat, unburdened by the precision, control, and picking speed associated with palm muting in the verses.

"Sugar" is definitely an improvised, not a choreographed video, but, like "Formation," it has moments that blur the binary. Two moments stand out to me as either having been pre-planned or rehearsed in some way. At 2:00, the bassist licks his fingers twice before forming them into a salute. Occurring just before a formal seam, the gesture is choreographed to a "three-and-four__" anacrusis that's just too perfect to have been improvised. From 2:56-3:02 the drummer takes advantage of a stop-time section, in which he merely crashes a cymbal every eight beats, to text-paint the lyrics with his unengaged drumsticks. On "number one with a bullet" he hoists a single stick high into the air (while mouthing the words). "Cock it and pull it" is intricately choreographed through a mimetic gesture with the drumsticks, in which he pulls back the hammer, fires a spinning drumstick-bullet, then crashes the cymbal directly on the beat.

\section{Conclusion: Music Videos as Music Theory}

In improvised dance, I take it as given that the dancers in the room are swerving all around each other, with every movement informing and informed by another's. The sounding music is part of that swerve as well. Each dancer's body is influenced by the rhythm, timbre, and form of the song. What may be surprising is that the music is also informed by the dancers. What I mean by this is that if we agree that there is no such thing as "the music itself" and instead turn our focus toward phenomenology (as does Lewin), then our object of study becomes the ways in which we perceive music. Do we not perceive the hypermetric downbeat at the beginning of chorus two (2:24) in the Fall Out Boy video as stronger because of the guitarist's vertical leap that lands precisely on that downbeat? If so, didn't the musician's physical movement (as a form of dance) just influence "the music?" The rich multimedia space of music videos is much like the cross-modal experience of dance, ${ }^{16}$ where movement and sound inform and are informed by one another.

Like most music theory focused on popular music, I have, at no point, made recourse to any published score for these two videos. 
Unlike much popular music theory, I'm not even creating transcriptions to bolster my observations. What I'm creating instead are analyses that focus on performance and performativity. It could well be the case that the experience of a music video could be impoverished by the mediation of transcription, that a turn toward performance and performativity entails being right in the middle of the action. Such a music theory isn't grounded in any written source, but rather comes from a Becoming-Music-Video: three planes-viewer, music, dancingall entangled in an interpretive swerve, each influencing each other.

Emily Dickinson captures the essence of such an entangled swerve in Poem \#556:

The Brain, within its Groove

Runs evenly-and true-

But let a Splinter swerve-

'Twere easier for You-

To put a Current back-

When Floods have slit the Hills-

And scooped a Turnpike for Themselves-

And trodden out the Mills- 


\section{POSTSCRIPT}

Several of John Rahn's seminars at the University of Washington were immeasurably influential on the scholar I was becoming at the time. One of those seminars: "Rhythm and Meter (and what about Dance?)" is clearly reflected in the current work. Others only tangentially so, but the list of my seminar paper titles shows just the kind of teacher that John was. He always encouraged such nonsense as: "Ritual Dismemberment and Drumming in the Matriarchal Cults of Ancient Greece" (seminar on Ancient Greek Music Theory); “(In)Finite State Apparatuses: An Althusserian Perspective on Musical Grammars" (seminar on Music and Mathematics); "Becoming-Music, Becoming-Intimate, Becoming-Imperceptible: Toward a Deleuzo-Guattarian Musicology" (seminar on Deleuze and Guattari); and "Beats that Commute: Algebraic and Kinesthetic Models for Math-Rock Grooves" (seminar on Rhythm and Meter).

$\mathrm{He}$ also demanded that such work was well reasoned. I got a C, and a stern talking-to, after the first one. The second was better. The third and fourth were published. There seems to be more and more push these days to mold students into ready-to-employ professionals with a definable set of skills that will serve them well in their first job. John never worried much about that. He was too busy teaching us how to create. 


\section{Notes}

1. Rahn $(2004,131)$.

2. Ibid.

3. Ibid.

4. Ibid., 135 .

5. Ibid., 138-39. Rahn names Milton Babbitt and Robert Morris among those theorists whose output may be most useful for composition, while somewhat tentatively suggesting that some of Allen Forte's output, though influential on these aforementioned thinkers, is somewhat more taxonomical in application.

6. Ibid., 134.

7. Ibid., 135 .

8. Ibid.

9. “Taxonomy is simple science" (Ibid.).

10. Elicker $(1998,72)$. Banks $(1997,295)$ defines performance videos as those that "portray groups performing the songs in a straightforward manner in front of the camera inside a studio or at a concert."

11. Vernallis's $(2004,18)$ view on narrativity in music videos is constrained by her position that most videos lack the true narrative structure of feature films. Vernallis claims that the narrative structure of music videos depends instead on visual rhythms: "in the absence of a strong narrative, music video creates tension by varying basic visual materials, such as shots and edits" (49).

12. Kaplan $(1987,55)$ for example, dismisses the performance video as "anti-narrative," while Elicker calls it a form of "psuedodocumentary" (1998, 72).

13. Cizmar (2009).

14. Rahn (2004, 132).

15. Two experienced Tango dancers might seem as if they are moving in perfectly composed unison even though they are improvising. This improvisation that appears composed is only possible because the dancers are drawing upon a library of learned moves-a type of choreography. 
16. On the multi-modal experience of dance, see Simpson-Litke and Stover (2019). 


\section{REFERENCES}

Banks, Jack. 1997. "Video in the Machine: The Incorporation of Music Video into the Recording Industry." Popular Music 16/3: 293-309.

Cizmar, Martin. 2009. "10 Emo Songs that Don’t Suck." The Phoenix Times (March 5).

Elicker, Martina. 1998. "Popular Music in the Age of the Video Clip." AAA: Arbeiten aus Anglistik und Amerikanistik 23/1: 69-89.

Rahn, John. 2004. “The Swerve and The Flow: Music's Relationship to Mathematics." Perspectives of New Music 42/1: 130-48.

Simpson-Litke, Rebecca, and Chris Stover. 2019. "Theorizing Fundamental Music/Dance Interactions in Salsa." Music Theory Spectrum 41/1: 74-103.

Vernallis, Carol. 2004. Experiencing Music Video: Aesthetics and Cultural Context. New York: Columbia University Press. 